\title{
Green synthesis of silver nanoparticles using the plant extract of Salvia spinosa grown in vitro and their antibacterial activity assessment
}

\author{
Saba Pirtarighat ${ }^{1} \cdot$ Maryam Ghannadnia $^{2} \cdot$ Saeid Baghshahi ${ }^{3}$
}

Received: 8 October 2018 / Accepted: 21 November 2018 / Published online: 4 December 2018

(c) The Author(s) 2018

\begin{abstract}
Researchers use bionanotechnology techniques as eco-friendly and cost-effective routes to fabricate nanoparticles and nanomaterials. The present study confirms the ability of plant extract of Salvia spinosa grown under in vitro condition for the biosynthesis of silver nanoparticles (Ag NPs) for the first time. The surface plasmon resonance found at $450 \mathrm{~nm}$ confirmed the formation of Ag NPs. Moreover, FESEM images showed that nanoparticles had spherical morphology. Furthermore, XRD analysis confirmed the crystalline nature of the particles. FTIR analysis was carried out to identify possible biomolecules responsible in bioreduction of silver ions. Antimicrobial assay verified bactericidal activity of biosynthesized Ag NPs against Gram-positive and Gram-negative bacteria. According to the results, by growing the plants under controlled conditions, it is feasible to synthesize nanoparticles with desired properties.
\end{abstract}

Maryam Ghannadnia

ghannadnia_ma@yahoo.com

1 Department of Biotechnology, Imam Khomeini International

University (IKIU), Qazvin, Islamic Republic of Iran

2 Department of Horticultural Science, Imam

Khomeini International University (IKIU), Qazvin,

Islamic Republic of Iran

3 Department of Materials Science and Engineering, Imam

Khomeini International University (IKIU), Qazvin,

Islamic Republic of Iran 


\section{Graphical abstract}
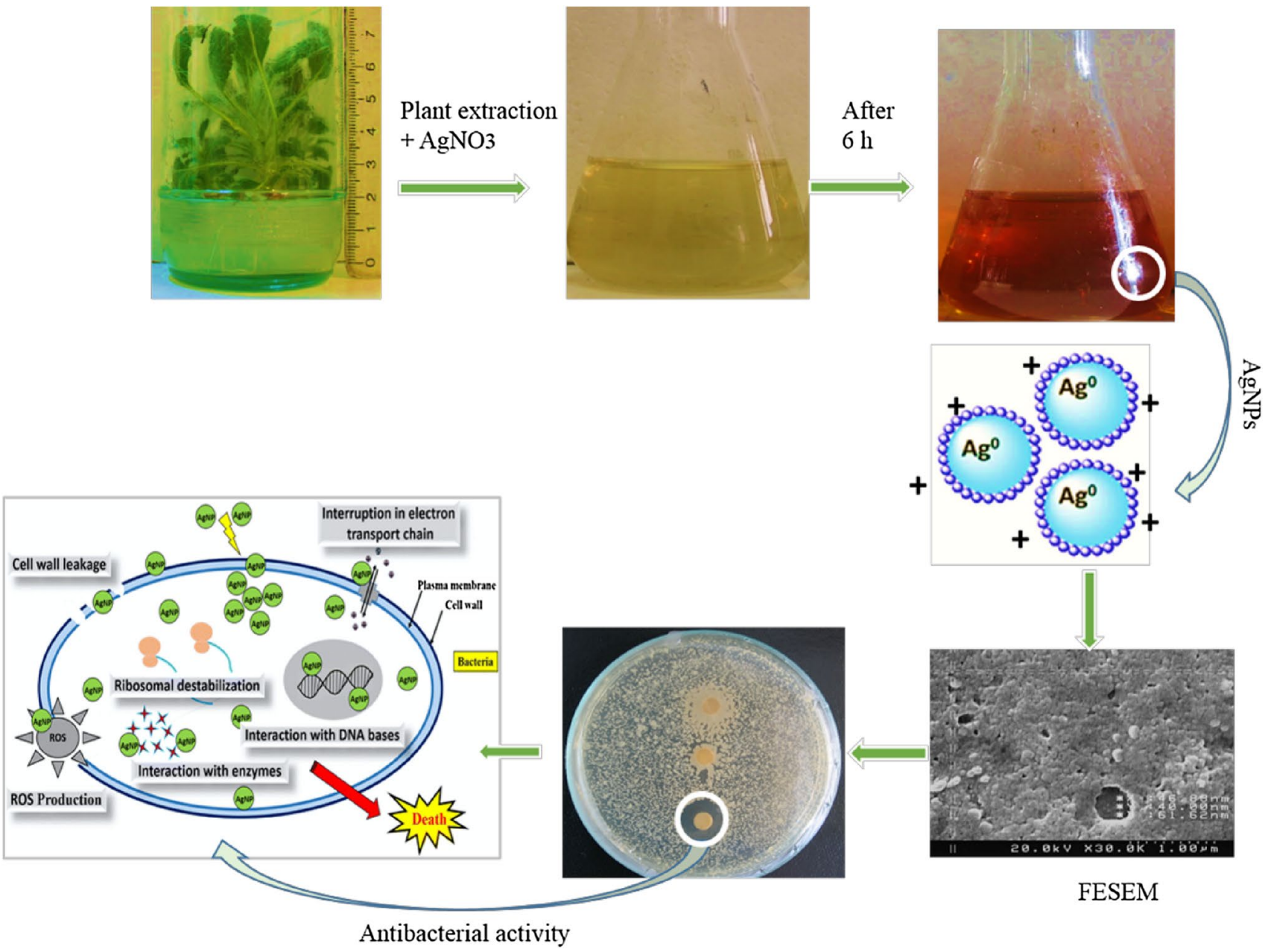

FESEM

Keywords Bio-nanotechnology $\cdot$ Salvia spinosa $\cdot$ Silver nanoparticles $\cdot$ Bactericidal activity

\section{Introduction}

Nanotechnology is the synthesis of particles with at least one dimension in the range of $1-100 \mathrm{~nm}$, resulting in high surface to volume ratios. As the particle size decreases, not only does the ratio of surface area to volume increase but also the physical, chemical and biological properties of the particles differ compared to their bulk counterparts [1, 2]. Noble-metal nanoparticles exhibit incredible physicochemical, optoelectronic and biochemical characteristics. They are being used for various purposes in industrial and pharmaceutical applications [3, 4]. Despite the existence of numerous metals in nature, only a few of them such as gold, silver, palladium and platinum are synthesized extensively in nanostructured form [5, 6]. Among the abovementioned metals, silver nanoparticles have attracted much attention due to their unique characteristics for utilizing in various applications including pharmaceutics, agriculture, water detoxification, air filtration, textile industries and as a catalyst in oxidization reactions [7-9]. Furthermore, their predominant property is their high antibacterial activity against a broad range of bacteria without any toxicity to animal cells [10-12]. The establishment of resistance to antibiotics in bacteria especially multidrug resistance compelled scientists to explore novel compounds to halt multidrug-resistant microorganisms. Bactericidal activity of Ag NPs without toxicity to human cells can make them a proper substitution for antibiotics [13, 14]. Ag NPs are being employed for eliminating microorganisms in medical devices, implants and hospital masks [15, 16]. They are also extensively being used in hospitals either supplemented with antibiotics or alone for preventing infection 
[17]. Nanoparticles are traditionally synthesized broadly by physical and chemical procedures. Chemically prepared nanoparticles are not appropriate for medical usages due to hazardous chemicals binding on their surface. Furthermore, by-products produced in chemical routes are toxic for the environment. Physical routes for synthesis of NPs have some drawbacks, too. These methods require high energy and space, and are expensive [18-20]. Using biological systems such as microorganisms, plants, viruses and animal cell cultures is an alternative procedure for preparation of NPs [21-23]. In the most recent studies, researchers utilized Gelidium amansii [24], Enteromorpha compressa [25], Phanerochaete chrysosporium [26], Bacillus brevis [27] and Daucus carota [28] for the biosynthesis of Ag NPs and investigated their antimicrobial properties. Biosynthesis of NPs is eco-friendly, time affordable, cost effective. More importantly, the biosynthesized NPs are free of hazardous material on their surface. Also, they may be coated with bioorganic compounds that make them proper for medical applications. These give biosynthesis of NPs distinct advantages over conventional methods [29, 30]. For example, NPs are used as a new tool for targeting in cancer therapy and the most important difficulty is toxicity of NPs synthesized by previous methods. Scientists overcome this issue using biologically synthesized NPs coated with biomolecules that are more biocompatible [31, 32].

Although the exact mechanism of NPs biosynthesis by various plant extracts is ambiguous, it has been revealed that the biomolecules in plant extract such as protein, phenol and flavonoids play a significant role in the reduction of metals ions and capping the biosynthesized nanoparticles [33]. Culturing plants in controlled environmental systems presents an approach for the production of specific bioactive molecules in plants [34]. Since these plants are not exposed to environmental turbulence, the metabolic production of these plants is not dependent on environmental changes [35].

Medicinal plants have served as rich sources of pharmacologically active substances. Herbs have been used in a diverse array of purposes, including medicine, nutrition, flavoring, dying, repellents, fragrances, cosmetic, charms, smoking and industrial uses. Today, herbs are still found in $40 \%$ of prescription drugs [36]. The genus Salvia from Lamiaceae family includes almost 900 species cultured or grown as a weed all around the world, mainly in the areas of the Central and South America, and Mediterranean and South Africa [37]. The product of this plant is used for culinary as spices and pharmaceutical purposes. This genus offers an economical cultivate for small farmers due to its usage in folk remedies and ornamental purposes [38, 39]. The metabolite content of Salvia genus has been investigated thoroughly several times. The presence of flavonoids, caffeic acid esters such as rosmarinic acid, and phenolic diterpenes such as carnosic acid and carnosol has been detected in Salvia species extracts $[34,40]$.

The extract of various plants grown in farms is used permanently for the biosynthesis of nanoparticles, but whether the plants grown under in vitro condition have this ability or not is still under scrutiny. The main purposes of this work are considering the potential of the plant extract of S. spinosa grown in vitro in Murashige and Skoog (MS) medium for the biosynthesis of Ag NPs and investigation of their antibacterial activities against both Gram-positive and Gram-negative species of bacteria.

\section{Materials and methods}

\section{Plant growth under in vitro condition}

Seeds of S. spinosa were purchased from Qazvin farmers. They were surface sterilized by ethanol $70 \%$ for $1 \mathrm{~min}$. After rinsing with sterile distilled water, sterilization was continued by soaking the seeds in sodium hypochlorite $2.5 \%$ for $5 \mathrm{~min}$. This process is followed by three times rising with sterile distilled water for $10 \mathrm{~min}$. Mineral salts, $3 \%$ sucrose and $4.5 \%$ agar were combined for Murashige and Skoog medium preparation and finally $\mathrm{pH}$ was adjusted at 5.8. After autoclaving, seeds were explanted in Petri dishes for germination. After germination, seedlings of the same age were subcultured into jars containing the same medium. These cultures were placed in the growth room at $25 \pm 2{ }^{\circ} \mathrm{C}$, in 16-/8-h period of day/night. After 2 months, plants were harvested and dried in oven at $37{ }^{\circ} \mathrm{C}$ for $48 \mathrm{~h}$.

\section{Preparation of plant extract}

All chemicals were provided from Merck or Aldrich. The dried plants were powdered with a mortar and pestle. $10 \mathrm{ml}$ of distilled water was poured to $0.2 \mathrm{~g}$ of plant powder. This combination was boiled for $5 \mathrm{~min}$ and then was cooled. The cooled solution was filtered with Whatman No. 1 filter paper.

\section{Biosynthesis of Silver nanoparticles}

Aqueous solution of silver nitrate $(1 \mathrm{mM})$ was prepared and mixed with fresh plant extract of $S$. spinosa at a ratio of 9:1. This solution was placed on a shaker with constant rotation in the room temperature at $27 \pm 2^{\circ} \mathrm{C}$ for $6 \mathrm{~h}$. All stages of the experiment were implemented in three replicates.

\section{Characterization of the silver nanoparticles}

Conventionally, characterization of particles is implemented by UV-Vis spectroscopy. An UV-Vis spectrophotometer (UVD 3200) was employed for verifying the biosynthesized 
Ag NPs. An Equinox 3000 diffractometer was utilized for XRD studies of Ag NPs. Furthermore, biosynthesized Ag NPs were observed by field-emission scanning electron microscopy (FESEM, HITACHI, S-4160). Particle size distribution of biosynthesized Ag NPs was obtained using Dynamic Light Scattering Malvern-Zetasizer (Nno-z 590). This study was undertaken to know the functional groups existed in plant extract responsible in silver ion reduction, so the pellets of plant extract and biosynthesized Ag NPs with potassium bromide $(1: 100)$ were used for FTIR spectrum analysis of plant extract and biosynthesized Ag NPs by a Bruker Tensor 27 spectrophotometer.

\section{Antibacterial activity of biosynthesized Ag NPs}

The antibacterial activity of the biosynthesized Ag NPs against Gram-positive and -negative bacteria species was done by disk diffusion method. Experimented bacteria were Bacillus subtilis (accession number: M59 KP406766), Bacillus vallismortis (accession number: M92 KP406765) and Escherichia coli (PTCC: 1276). Bacterial strains were spread on the Petri dishes which contained autoclaved Luria-Bertani (LB) medium containing agar. Then, the disks $(6 \mathrm{~mm}$ diameter) soaked in distilled water as a control, plant extract and biosynthesized Ag NPs were separately placed on Petri dishes containing LB media. Petri dishes were incubated at $37^{\circ} \mathrm{C}$. Inhibition zone of each disk was measured by ruler after $18 \mathrm{~h}$.

\section{Results and discussion}

\section{Color change of solution}

In this study, we cultured plants in vitro under controlled conditions and used these plants for considering their potential for reduction of Ag ions. The fresh extract of $S$. spinosa was yellow in color, but after addition of $\mathrm{AgNO}_{3}$ solution and stirring at room temperature, gradually the solution color changed into red (Fig. 1). In other words, by passing the incubation time, the color intensity increased, which confirmed Ag ion reduction and the formation of Ag NPs [41]. Silver nanoparticle surface plasmon excitation causes color change in the solution [42], which is the primary and notable evidence for the formation of Ag NPs [43].

\section{UV-Vis analysis}

UV-Vis absorption spectrum of Ag NPs is shown in Fig. 2. Broad bell-shaped spectrum curve was obtained from UV-Vis analysis. Various metabolites from plant extract introduced to solution make the plasmon band broad because they may be read in this spectrophotometric range, too. Surface plasmon resonance (SPR) of silver occurs at $450 \mathrm{~nm}$. This peak increased with time up to $360 \mathrm{~min}$. According to Mie theory, spherical nanoparticles show only a single SPR band. The number of peaks increases by increasing diversity of particles shapes $[43,44]$. Then, it can be concluded that biosynthesized Ag NPs are unanimously spherical in nature.

\section{X-ray diffraction analysis}

XRD pattern revealed distinct peaks at $2 \theta$ values, which can be attributed to 111, 200, 220 and 311 crystalline planes of Ag NPs (Fig. 3). These peaks are associated with the facecentered cubic lattice [45]. Other peaks at $2 \theta$ values in $\mathrm{Ag}$ NPs pattern can be ascribed to the residues of the organic content of the plant extract. These peaks reveal the crystallization of some plant metabolite moieties on the surface of the Ag NPs, which is in agreement with Shanmuganathan et al.'s results [28]. This is an acceptable evidence to confirm the involvement of the plant extract compositions in the Ag NP formation. This result is in accordance with XRD analysis of Oves et al. [46]. Although the exact mechanism of biosynthesis procedure by plant extract is not clear, the role of the secondary metabolites in biosynthesis process
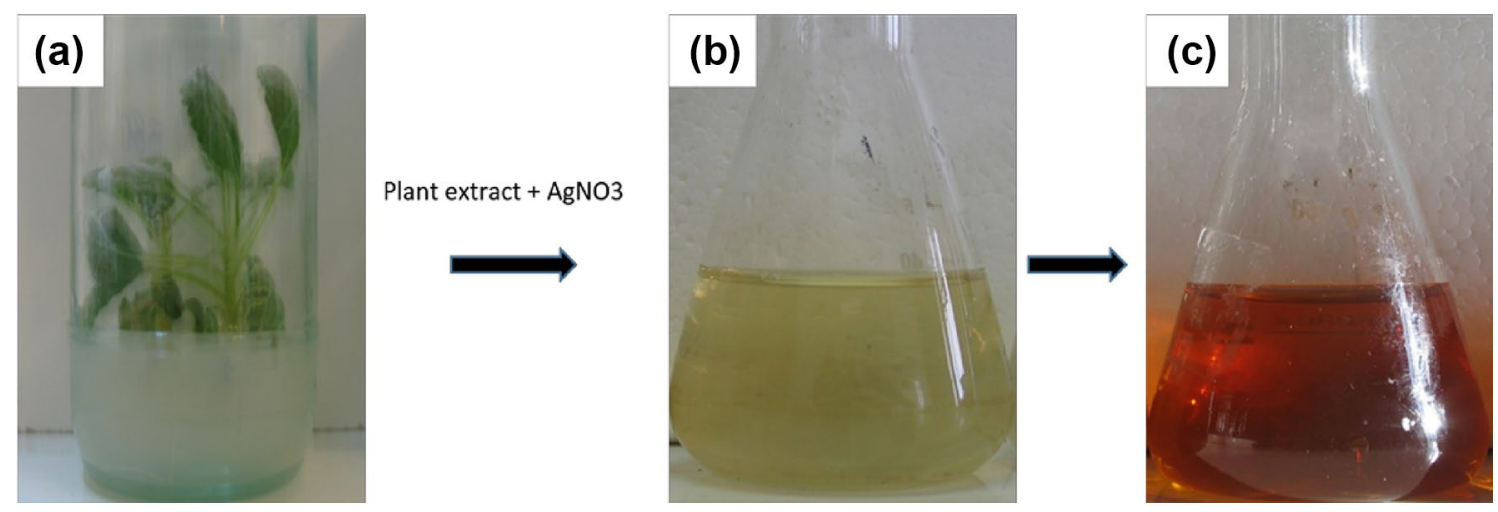

Fig. 1 Color changes in the plant extract after adding $\mathrm{AgNO}_{3}$ solution. a $S$. spinosa grown in vitro b 5 min and $\mathbf{c} 6 \mathrm{~h}$ after reaction 
Fig. 2 UV-Vis absorption spectra of silver nanoparticles biosynthesized by $S$. spinosa extract during reaction

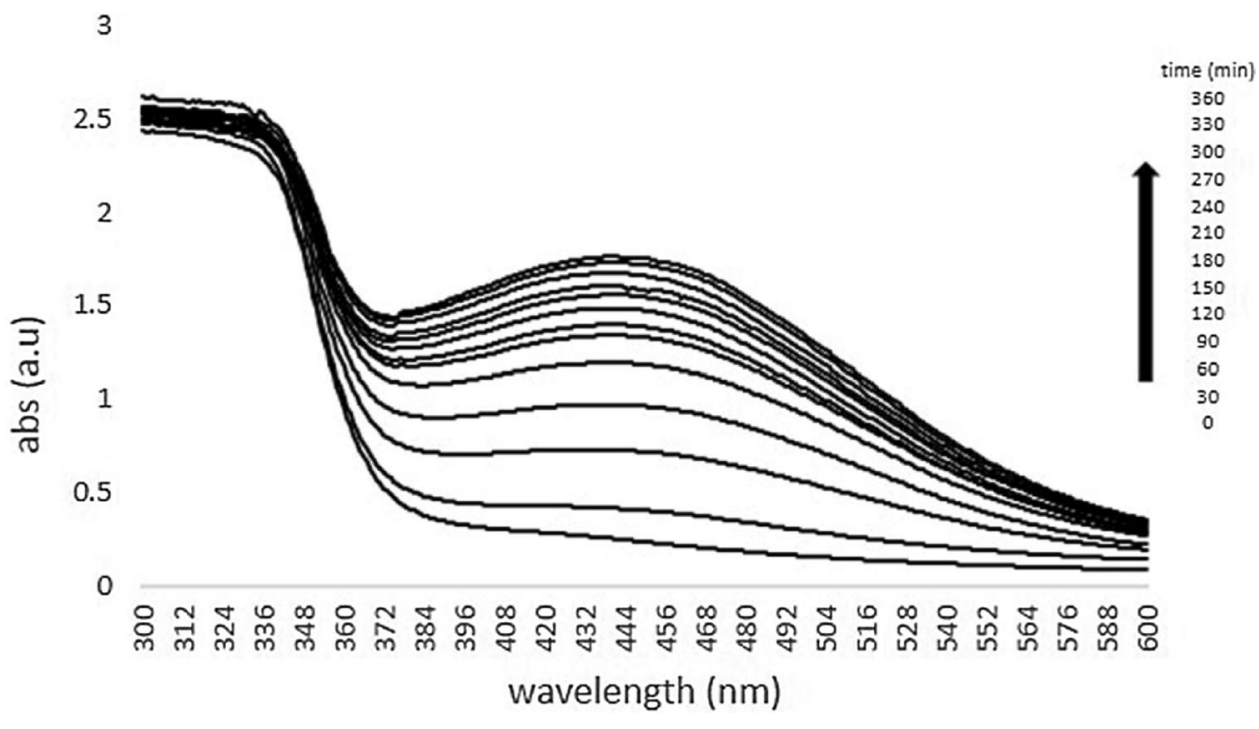

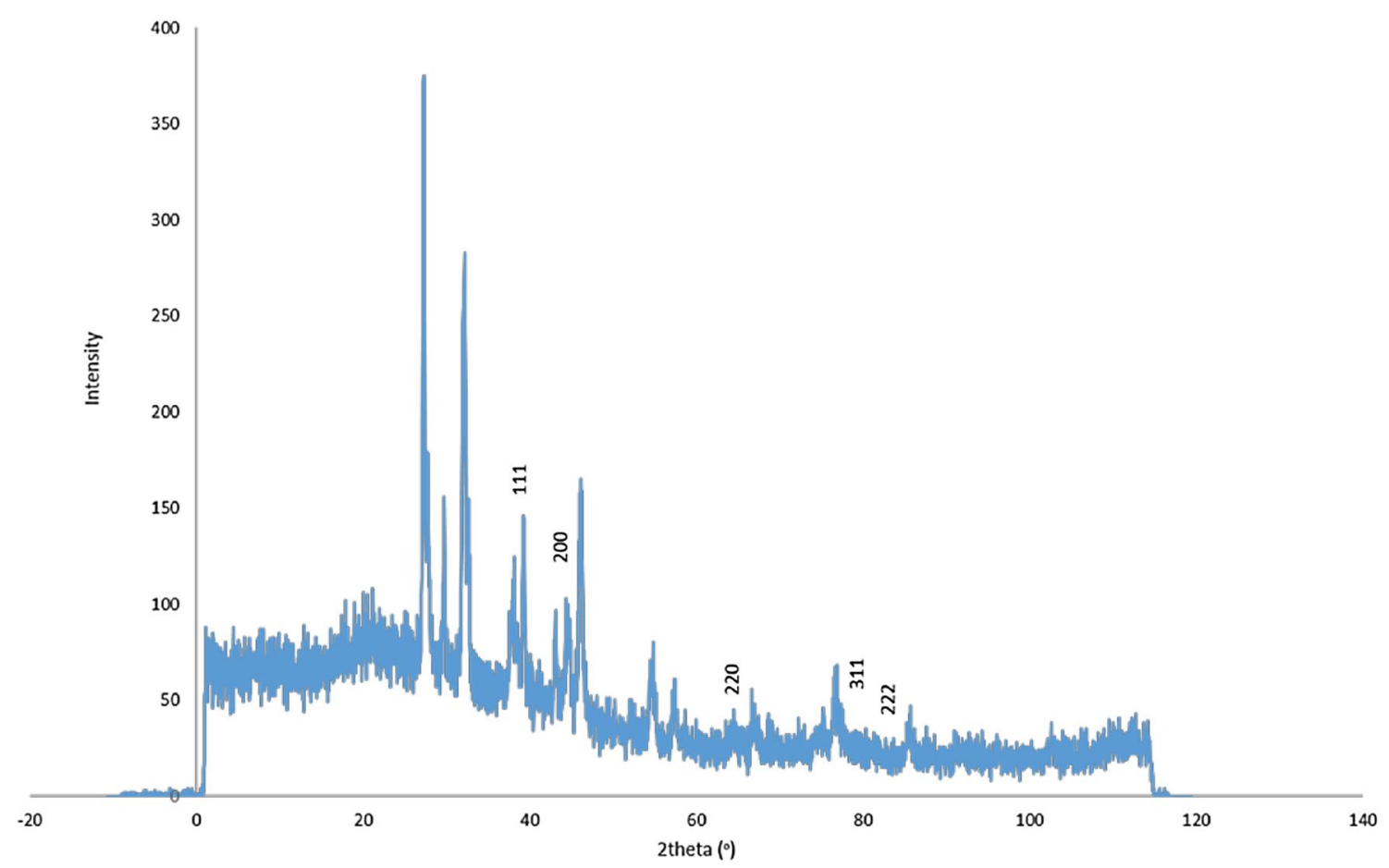

Fig. $3 \mathrm{X}$ ray diffraction profile from dried silver nanoparticles biosynthesized by $S$. spinosa extract

is undeniable. The presence of carnosic acid and flavonoids, which contain carboxylate group, have been detected in Salvia species extracts [34]. Interactions between these metabolites and silver ions cause the bioreduction of silver nitrate and synthesis of Ag NPs. Negatively charged groups presented in the plant extract such as carboxylate $\left(\mathrm{COO}^{-}\right)$ and polar groups such as $\mathrm{OH}$ and $\mathrm{CO}$ have a high tendency to attach on the surface of the $\mathrm{Ag}^{+}$. So, these groups contribute in both reduction and stabilization of $\mathrm{Ag}$ ions [47]. It can be concluded that plant metabolites containing $\mathrm{OH}$,
$\mathrm{CO}$ and especially $\mathrm{COO}^{-}$such as carnosic acid, flavonoids and proteins have a pivotal role in the possible mechanism for bioreduction of silver ions.

\section{FESEM and DLS analysis}

The morphology of the Ag NPs was analyzed through FESEM images (Fig. 4a, b). The majority of particles were spherical in shape and there were a few oval Ag NPs as well. Biosynthesized Ag NPs had been spread thoroughly in the 

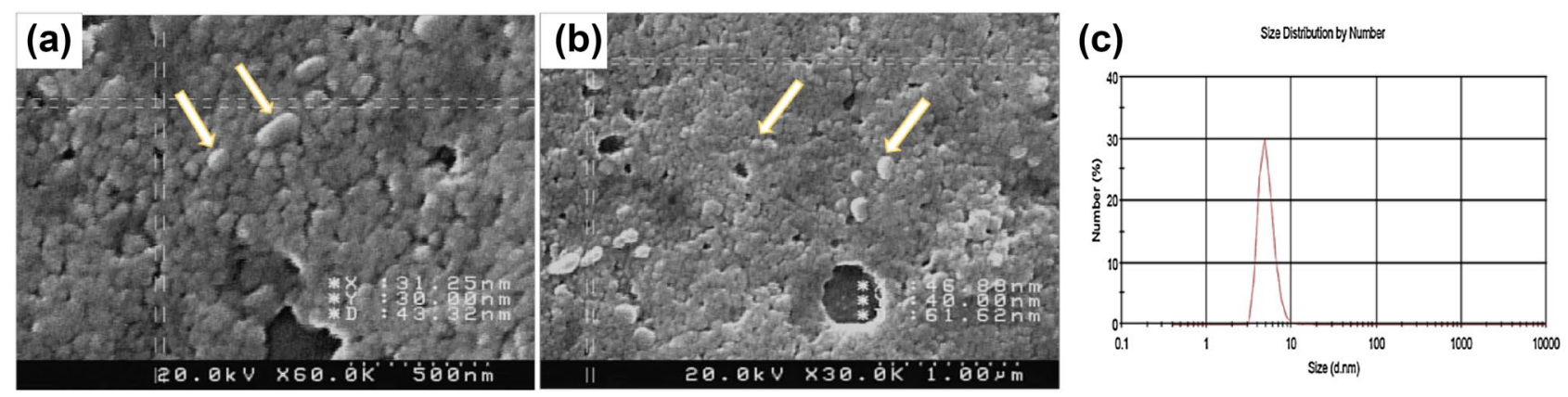

Fig. 4 a) FESEM images scale in $\mathbf{a} 500 \mathrm{~nm}$ and $\mathbf{b} 1 \mu \mathrm{m}$. Nanoparticles coated with organic materials of plant extract have been indicated with arrows in two pictures $\mathbf{c}$ particle diameter analysis from Ag NPs biosynthesized by S. spinosa extract

solution. The size of some selected biosynthesized nanoparticles was 19-125 $\mathrm{nm}$ according to FESEM images. The average diameter of total particles was measured by dynamic light scattering (DLS) analysis. The majority of the Ag NPs were $5.13 \mathrm{~nm}$ in diameter (Fig. 4c). The biomolecule coating of the biosynthesized Ag NPs is shown in the FESEM images. This layer confirms plant extract metabolites' role in the synthesis and stabilizing of the biosynthesized $\mathrm{Ag}$ NPs. These results are in agreement with Oves et al.'s [46] findings.

\section{Fourier infrared spectroscopy analysis}

FTIR spectra of the biosynthesized silver nanoparticles and the aqueous plant extract are shown in Fig. 5. Responsible metabolites for reduction of $\mathrm{Ag}$ ions were detected using
FTIR spectrum. Instinct absorption bands at 3423.15 and $3420.77 \mathrm{~cm}^{-1}$ appear in the presence of phenols and alcohols with free OH group [48]. This band is superimposed by NH stretching peak [49]. The bands at 2928.45 and $2928.44 \mathrm{~cm}^{-1}$ represent the presence of alkanes in lipids [48]. The region of $2359.03 \mathrm{~cm}^{-1}$ indicates the presence of symmetric stretching of $\mathrm{COO}^{-}$just in the biosynthesized solution [47]. The bands at 2240.59 and $2241.03 \mathrm{~cm}^{-1}$ are assigned to the $\mathrm{C} \equiv \mathrm{C}$ group. The bands at 2138.93 and $2138.90 \mathrm{~cm}^{-1}$ reveal the presence of alkynes, N-C and $\mathrm{N}=\mathrm{C}$ groups in $\mathrm{R}-\mathrm{N}=\mathrm{C}=\mathrm{S}$ structure. The absorption bands at 1630.32 and $1631.43 \mathrm{~cm}^{-1}$ are corresponded to the $\mathrm{C}=\mathrm{C}$ in aromatic compounds and amide I (NH out of plane) [50, 51]. The bands at 1518.75 and $1518.92 \mathrm{~cm}^{-1}$ are due to the amide II in proteins [51]. The bands at 1406.56 and 1407.48 $\mathrm{cm}^{-1}$ indicate $\mathrm{S}=\mathrm{O}$ (sulfate ester) group. The bands at 1123

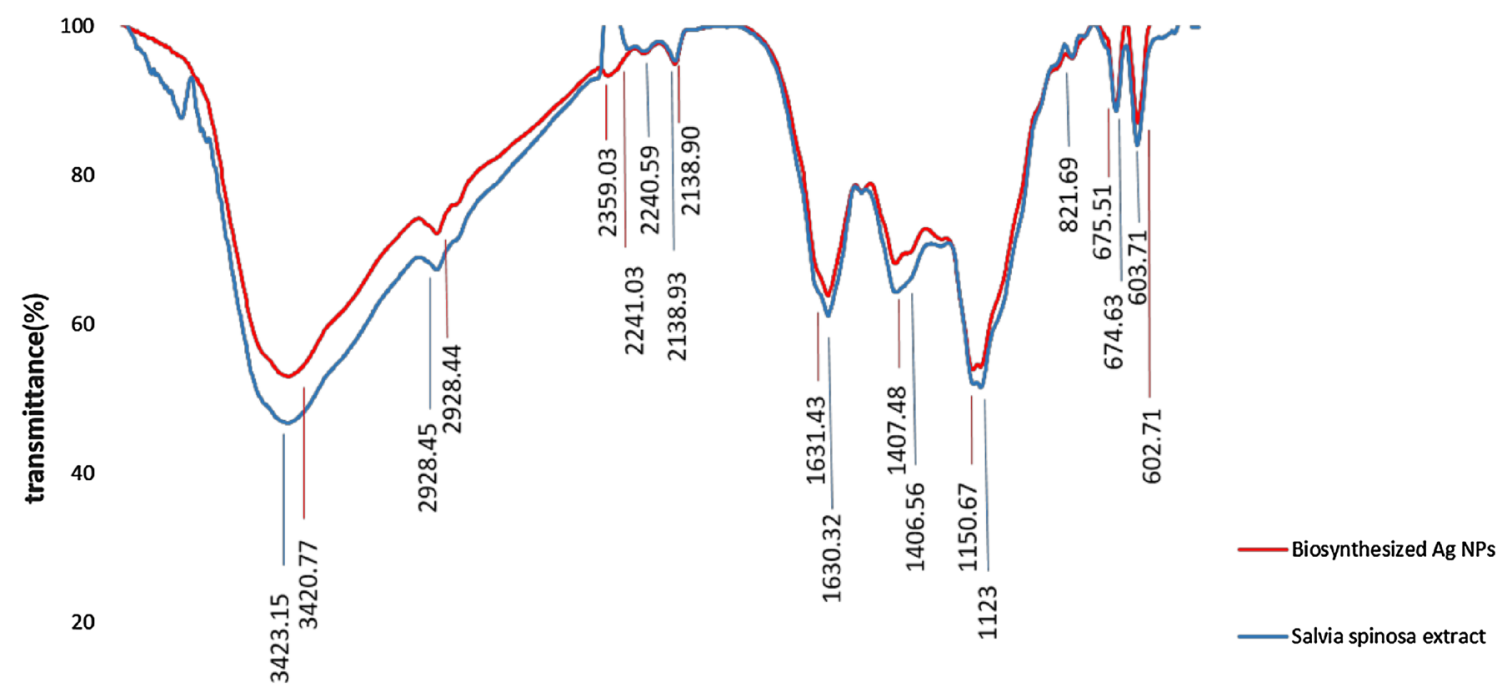

$\begin{array}{llllllll}0 & 3596 & 3013 & 2521 & 2029 & 1537 & 1045 & 554 \\ & & & \text { Wavenumber }(\mathrm{cm}-1) & & & \end{array}$

Fig. 5 FTIR spectra of biosynthesized Ag NPs by S. spinosa extract and S. spinosa extract 

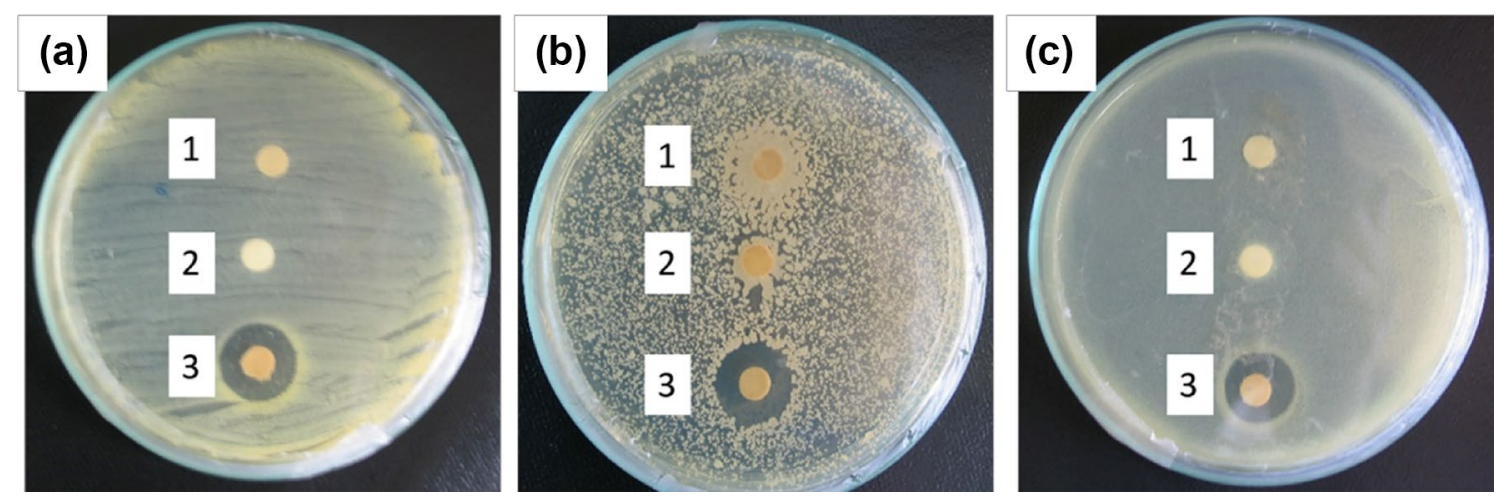

Fig. 6 Bactericidal activity of (1) S. spinosa extract, (2) distilled water and (3) biosynthesized Ag NPs from S. spinosa extract, against a E. coli, b $B$. subtilis and $\mathbf{c} B$. vallismortis

and $1150.67 \mathrm{~cm}^{-1}$ confirmed the presence of carboxylic acid group. The bands at 821.69 and $\mathrm{cm}^{-1}$, and also 674.63 and $675.51 \mathrm{~cm}^{-1}$ represent the presence of $=\mathrm{CH}$ in aromatic compounds in the plant extract and the biosynthesized Ag NPs. The bands at 603.71 and $602.71 \mathrm{~cm}^{-1}$ correspond to the $\mathrm{C}-\mathrm{Cl}$ (alkyl halides). First number belongs to the plant extract and second to the Ag NPs. Free carboxylate groups presented in proteins can bind to the metal nanoparticles and make them stable [47]. Only minor changes in the position of absorption bands between FTIR spectrum of the plant extract and biosynthesized Ag NPs were seen. The involvement of plant extract compounds in biosynthesizing of nanoparticles was confirmed with shifting of peaks. Thus, plant extract compounds including $\mathrm{OH}$ and $\mathrm{CO}$ groups have a vital role in reducing and stabilization of NPs [52].

\section{Antibacterial activity of the Ag NPs}

Antibacterial activity of the biosynthesized Ag NPs is shown in Fig. 6. Distilled water was utilized as a control. The measured diameter for the restriction area for the growth of bacteria in B. subtilis, B. vallismortis and E. coli were 15, 16 and 12 , respectively. This result indicates that Gram-positive bacteria are more sensitive than Gram-negative bacteria. The bactericidal activity of Ag NPs against broad range of bacteria has been proven in several studies. This potential of Ag NPs confirms multifaceted strategy of Ag NPs in the bacteria exposure [53]. The mechanism of bactericidal activity of Ag NPs is most likely due to the attachment of the Ag NPs to the cell wall and the generation of free radicals. Moreover, the presence of Ag NPs in the cell membrane of bacteria has been proven in earlier studies [46]. Ag NPs disturb the permeability of the membrane by penetrating to the cell membrane and causing intracellular ATP leakage and cell death [47, 54]. Silver ions' release from Ag NPs acting as reservoir causes antibacterial activity of Ag NPs [47]. It appears that the positively charged ions such as $\mathrm{Ag}^{+}$in this experiment have a high tendency to act with phosphorus and sulfur presented in biomolecules such as DNA and RNA. Such an attachment results in the disruption of DNA and RNA functions [54, 55].

\section{Conclusion}

Biosynthesis of Ag NPs using plant extract of S. spinosa grown in vitro under controlled condition was carried out for the first time in this study. This study confirmed S. spinosa's (cultured under controlled condition) capability for the biosynthesis of Ag NPs. The characteristics of the biosynthesized Ag NPs were measured by different equipments. Moreover, bactericidal activity assessment of the biosynthesized Ag NPs showed their inhibitory function against both Gram-positive and Gram-negative bacteria. In this study, possible functional groups and effective compounds responsible in reduction of silver ions were assigned. The speculated mechanism in this work elucidates the involvement of carboxylic acid functional group presented in carnosic acid and flavonoids in the bioreduction process and the stabilization of biosynthesized Ag NPs.

Acknowledgements Authors are thankful for Imam Khomeini International University authorities for supporting this work.

\section{Compliance with ethical standards}

Conflict of interest The authors declare that they have no conflict of interest.

Open Access This article is distributed under the terms of the Creative Commons Attribution 4.0 International License (http://creativeco mmons.org/licenses/by/4.0/), which permits unrestricted use, distribution, and reproduction in any medium, provided you give appropriate credit to the original author(s) and the source, provide a link to the Creative Commons license, and indicate if changes were made. 


\section{References}

1. Dos Santos, C.A., Seckler, M.M., Ingle, A.P., Gupta, I., Galdiero, S., Galdiero, M., Gade, A., Rai, M.: Silver nanoparticles: therapeutical uses, toxicity, and safety issues. J. Pharm. Sci. 103, 19311944 (2014)

2. Narayanan, K.B., Sakthivel, N.: Biological synthesis of metal nanoparticles by microbes. Adv. Colloid Interface Sci. 156, $1-13(2010)$

3. Linic, S., Aslam, U., Boerigter, C., Morabito, M.: Photochemical transformations on plasmonic metal nanoparticles. Nat. Mater. 14, 567-576 (2015)

4. Thakkar, K.N., Mhatre, S.S., Parikh, R.Y.: Biological synthesis of metallic nanoparticles. Nanomed. Nanotechnol. Biol. Med. 6, 257-262 (2010)

5. Yoon, W.-J., Jung, K.-Y., Liu, J., Duraisamy, T., Revur, R., Teixeira, F.L., Sengupta, S., Berger, P.R.: Plasmon-enhanced optical absorption and photocurrent in organic bulk heterojunction photovoltaic devices using self-assembled layer of silver nanoparticles. Sol. Energy Mater. Sol. Cells 94, 128-132 (2010)

6. Yang, Y., Jin, P., Zhang, X., Ravichandran, N., Ying, H., Yu, C., Ying, H., Xu, Y., Yin, J., Wang, K.: New epigallocatechin gallate (EGCG) nanocomplexes co-assembled with 3-mercapto1 -hexanol and $\beta$-lactoglobulin for improvement of antitumor activity. J. Biomed. Nanotechnol. 13, 805-814 (2017)

7. Sathishkumar, M., Sneha, K., Won, S., Cho, C.-W., Kim, S., Yun, Y.-S.: Cinnamon zeylanicum bark extract and powder mediated green synthesis of nano-crystalline silver particles and its bactericidal activity. Colloids Surf. B 73, 332-338 (2009)

8. Gan, L., Zhang, S., Zhang, Y., He, S., Tian, Y.: Biosynthesis, characterization and antimicrobial activity of silver nanoparticles by a halotolerant Bacillus endophyticus SCU-L. Prep. Biochem. Biotechnol. A (2018). https://doi.org/10.1080/10826 068.2018.1476880

9. Arvizo, R.R., Bhattacharyya, S., Kudgus, R.A., Giri, K., Bhattacharya, R., Mukherjee, P.: Intrinsic therapeutic applications of noble metal nanoparticles: past, present and future. Chem. Soc. Rev. 41, 2943-2970 (2012)

10. Elechiguerra, J.L., Burt, J.L., Morones, J.R., Camacho-Bragado, A., Gao, X., Lara, H.H., Yacaman, M.J.: Interaction of silver nanoparticles with HIV-1. J. Nanobiotechnol. 3, 6 (2005). https ://doi.org/10.1186/1477-3155-3-6

11. Yeo, S.Y., Lee, H.J., Jeong, S.H.: Preparation of nanocomposite fibers for permanent antibacterial effect. J. Mater. Sci. 38, 2143-2147 (2003)

12. Elshawy, O.E., Helmy, E.A., Rashed, L.A.: Preparation, characterization and in vitro evaluation of the antitumor activity of the biologically synthesized silver nanoparticles. Adv. Nanopart. 5, 149-166 (2016)

13. Leid, J.G., Ditto, A.J., Knapp, A., Shah, P.N., Wright, B.D., Blust, R., Christensen, L., Clemons, C., Wilber, J., Young, G.W.: In vitro antimicrobial studies of silver carbene complexes: activity of free and nanoparticle carbene formulations against clinical isolates of pathogenic bacteria. J. Antimicrob. Chemother. 67, 138-148 (2011)

14. Modi, S.R., Collins, J.J., Relman, D.A.: Antibiotics and the gut microbiota. J. Clin. Investig. 124, 4212-4218 (2014)

15. Ansari, M., Khan, H., Khan, A., Cameotra, S., Alzohairy, M.: Anti-biofilm efficacy of silver nanoparticles against MRSA and MRSE isolated from wounds in a tertiary care hospital. Indian J. Med. Microbiol. 33, 101-109 (2015)

16. Bosetti, M., Masse, A., Tobin, E., Cannas, M.: Silver coated materials for external fixation devices: in vitro biocompatibility and genotoxicity. Biomaterials 23, 887-892 (2002)
17. Shahverdi, A.R., Fakhimi, A., Shahverdi, H.R., Minaian, S.: Synthesis and effect of silver nanoparticles on the antibacterial activity of different antibiotics against Staphylococcus aureus and Escherichia coli. Nanomed. NBM 3, 168-171 (2007)

18. Gade, A., Bonde, P., Ingle, A., Marcato, P., Duran, N., Rai, M.: Exploitation of Aspergillus niger for synthesis of silver nanoparticles. J. Biobased Mater. Bioenergy 2, 243-247 (2008)

19. Ouda, S.M.: Antifungal activity of silver and copper nanoparticles on two plant pathogens, Alternaria alternata and Botrytis cinerea. Res. J. Microbiol. 9, 34-42 (2014)

20. Wei, X., Luo, M., Li, W., Yang, L., Liang, X., Xu, L., Kong, P., Liu, H.: Synthesis of silver nanoparticles by solar irradiation of cell-free Bacillus amyloliquefaciens extracts and $\mathrm{AgNO}_{3}$. Bioresour. Technol. 103, 273-278 (2012)

21. Naik, R.R., Stringer, S.J., Agarwal, G., Jones, S.E., Stone, M.O.: Biomimetic synthesis and patterning of silver nanoparticles. Nat. Mater. 1, 169-172 (2002)

22. Fayaz, A.M., Balaji, K., Girilal, M., Yadav, R., Kalaichelvan, P.T., Venketesan, R.: Biogenic synthesis of silver nanoparticles and their synergistic effect with antibiotics: a study against grampositive and gram-negative bacteria. Nanomed. NBM 6, 103-109 (2010)

23. Singhal, G., Bhavesh, R., Kasariya, K., Sharma, A.R., Singh, R.P.: Biosynthesis of silver nanoparticles using Ocimum sanctum (Tulsi) leaf extract and screening its antimicrobial activity. J. Nanopart. Res. 13, 2981-2988 (2011)

24. Pugazhendhi, A., Prabakar, D., Jacob, J.M., Karuppusamy, I., Saratale, R.G.: Synthesis and characterization of silver nanoparticles using Gelidium amansii and its antimicrobial property against various pathogenic bacteria. Microb. Pathog. 114, 41-45 (2018)

25. Ramkumar, V.S., Pugazhendhi, A., Gopalakrishnan, K., Sivagurunathan, P., Saratale, G.D., Dung, T.N.B., Kannapiran, E.: Biofabrication and characterization of silver nanoparticles using aqueous extract of seaweed Enteromorpha compressa and its biomedical properties. Biotechnol. Rep. 14, 1-7 (2017)

26. Saravanan, M., Arokiyaraj, S., Lakshmi, T., Pugazhendhi, A.: Synthesis of silver nanoparticles from Phanerochaete chrysosporium (MTCC-787) and their antibacterial activity against human pathogenic bacteria. Microb. Pathog. 117, 68-72 (2018)

27. Saravanan, M., Barik, S.K., MubarakAli, D., Prakash, P., Pugazhendhi, A.: Synthesis of silver nanoparticles from Bacillus brevis (NCIM 2533) and their antibacterial activity against pathogenic bacteria. Microb. Pathog. 116, 221-226 (2018)

28. Shanmuganathan, R., MubarakAli, D., Prabakar, D., Muthukumar, H., Thajuddin, N., Kumar, S.S., Pugazhendhi, A.: An enhancement of antimicrobial efficacy of biogenic and ceftriaxone-conjugated silver nanoparticles: green approach. Environ. Sci. Pollut. Res. 25, 10362-10370 (2018)

29. Mukherjee, P., Roy, M., Mandal, B., Dey, G., Mukherjee, P., Ghatak, J., Tyagi, A., Kale, S.: Green synthesis of highly stabilized nanocrystalline silver particles by a non-pathogenic and agriculturally important fungus T. asperellum. Nanotechnology 19, 75103-75110 (2008)

30. Bar, H., Bhui, D.K., Sahoo, G.P., Sarkar, P., De, S.P., Misra, A.: Green synthesis of silver nanoparticles using latex of Jatropha curcas. Colloids Surf. A 339, 134-139 (2009)

31. Pugazhendhi, A., Edison, T.N.J.I., Karuppusamy, I., Kathirvel, B.: Inorganic nanoparticles: a potential cancer therapy for human welfare. Int. J. Pharm. 539, 104-111 (2018)

32. Khandekar, S.V., Kulkarni, M., Devarajan, P.V.: Polyaspartic acid functionalized gold nanoparticles for tumor targeted doxorubicin delivery. J. Biomed. Nanotechnol. 10, 143-153 (2014)

33. Krishnaraj, C., Jagan, E., Rajasekar, S., Selvakumar, P., Kalaichelvan, P., Mohan, N.: Synthesis of silver nanoparticles using Acalypha indica leaf extracts and its antibacterial activity against water borne pathogens. Colloids Surf. B 76, 50-56 (2010) 
34. Luis, J.G.: Chemistry, biogenesis, and chemotaxonomy of the diterpenoids of Salvia. In: Harborne, J.B., Tomas-Barberan, F.A. (eds.) Ecological Chemistry and Biochemistry of Plant Terpenoids, pp. 63-82. Clarendon Press, Oxford (1991)

35. Grzegorczyk, I., Matkowski, A., Wysokińska, H.: Antioxidant activity of extracts from in vitro cultures of Salvia officinalis L. Food Chem. 104, 536-541 (2007)

36. Newman, D.J., Cragg, G.M.: Natural products as sources of new drugs over the last 25 years. J. Nat. Prod. 70, 461-477 (2007)

37. Delamare, A.P.L., Moschen-Pistorello, I.T., Artico, L., AttiSerafini, L., Echeverrigaray, S.: Antibacterial activity of the essential oils of Salvia officinalis L. and Salvia triloba L. cultivated in South Brazil. Food Chem. 100, 603-608 (2007)

38. Maksimović, M., Vidic, D., Miloš, M., Šolić, M.E., Abadžić, S., Siljak-Yakovlev, S.: Effect of the environmental conditions on essential oil profile in two Dinaric Salvia species: S. brachyodon Vandas and S. officinalis L. Biochem. Syst. Ecol. 35, 473-478 (2007)

39. Taarit, M.B., Msaada, K., Hosni, K., Hammami, M., Kchouk, M.E., Marzouk, B.: Plant growth, essential oil yield and composition of sage (Salvia officinalis L.) fruits cultivated under salt stress conditions. Ind. Crops Prod. 30, 333-337 (2009)

40. Grzegorczyk, I., Bilichowski, I., Mikiciuk-Olasik, E., Wysokinska, H.: In vitro cultures of Salvia officinalis L. as a source of antioxidant compounds. Acta Soc. Bot. Pol. 74, 17-21 (2005)

41. Chandran, S.P., Chaudhary, M., Pasricha, R., Ahmad, A., Sastry, M.: Synthesis of gold nanotriangles and silver nanoparticles using Aloe vera plant extract. Biotechnol. Prog. 22, 577-583 (2006)

42. Kumar, P., Selvi, S.S., Govindaraju, M.: Seaweed-mediated biosynthesis of silver nanoparticles using Gracilaria corticata for its antifungal activity against Candida spp. Appl. Nanosci. 3, 495-500 (2013)

43. Banerjee, P., Satapathy, M., Mukhopahayay, A., Das, P.: Leaf extract mediated green synthesis of silver nanoparticles from widely available Indian plants: synthesis, characterization, antimicrobial property and toxicity analysis. Bioresour. Bioprocess. 1, 1-10 (2014)

44. Raut Rajesh, W., Lakkakula Jaya, R., Kolekar Niranjan, S., Mendhulkar Vijay, D., Kashid Sahebrao, B.: Phytosynthesis of silver nanoparticle using Gliricidia sepium (Jacq.). Curr. Nanosci. 5, 117-122 (2009)

45. de Jesús Ruíz-Baltazar, Á., Reyes-López, S.Y., Larrañaga, D., Estévez, M., Pérez, R.: Green synthesis of silver nanoparticles using a Melissa officinalis leaf extract with antibacterial properties. Results Phys. 7, 2639-2643 (2017)

46. Oves, M., Aslam, M., Rauf, M.A., Qayyum, S., Qari, H.A., Khan, M.S., Alam, M.Z., Tabrez, S., Pugazhendhi, A., Ismail,
I.M.: Antimicrobial and anticancer activities of silver nanoparticles synthesized from the root hair extract of Phoenix dactylifera. Mater. Sci. Eng. C 89, 429-443 (2018)

47. Ajitha, B., Reddy, Y.A.K., Reddy, P.S.: Biogenic nano-scale silver particles by Tephrosia purpurea leaf extract and their inborn antimicrobial activity. Spectrochimica Acta, Part A 121, 164-172 (2014)

48. Vanaja, M., Gnanajobitha, G., Paulkumar, K., Rajeshkumar, S., Malarkodi, C., Annadurai, G.: Phytosynthesis of silver nanoparticles by Cissus quadrangularis: influence of physicochemical factors. J. Nanostruct. Chem. 3, 1-8 (2013)

49. Suresh, S., Karthikeyan, S., Jayamoorthy, K.: FTIR and multivariate analysis to study the effect of bulk and nano copper oxide on peanut plant leaves. J. Sci. Adv. Mater. Devices. 1, 343-350 (2016)

50. Raghunandan, D., Bedre, M.D., Basavaraja, S., Sawle, B., Manjunath, S., Venkataraman, A.: Rapid biosynthesis of irregular shaped gold nanoparticles from macerated aqueous extracellular dried clove buds (Syzygium aromaticum) solution. Colloids Surf. B 79, 235-240 (2010)

51. Stehfest, K., Toepel, J., Wilhelm, C.: The application of microFTIR spectroscopy to analyze nutrient stress-related changes in biomass composition of phytoplankton algae. Plant Physiol. Biochem. 43, 717-726 (2005)

52. Sre, P.R., Reka, M., Poovazhagi, R., Kumar, M.A., Murugesan, K.: Antibacterial and cytotoxic effect of biologically synthesized silver nanoparticles using aqueous root extract of Erythrina indica lam. Spectrochim. Acta, Part A 135, 1137-1144 (2015)

53. Franci, G., Falanga, A., Galdiero, S., Palomba, L., Rai, M., Morelli, G., Galdiero, M.: Silver nanoparticles as potential antibacterial agents. Molecules 20, 8856-8874 (2015)

54. Hajipour, M.J., Fromm, K.M., Ashkarran, A.A., de Aberasturi, D.J., de Larramendi, I.R., Rojo, T., Serpooshan, V., Parak, W.J., Mahmoudi, M.: Antibacterial properties of nanoparticles. Trends Biotechnol. 30, 499-511 (2012)

55. Umashankari, J., Inbakandan, D., Ajithkumar, T.T., Balasubramanian, T.: Mangrove plant, Rhizophora mucronata (Lamk, 1804) mediated one pot green synthesis of silver nanoparticles and its antibacterial activity against aquatic pathogens. Aquat. Biosyst. 8, 1-8 (2012)

Publisher's Note Springer Nature remains neutral with regard to jurisdictional claims in published maps and institutional affiliations. 